\title{
Apoptotic-inducing activity of novel polycyclic aromatic compounds in human leukemic cells
}

\author{
KRISTIN R. LANDIS-PIWOWAR ${ }^{1}$, DI CHEN ${ }^{1}$, QIUZHI CINDY CUI ${ }^{1}$, VESNA MINIC $^{1}$, \\ FREDERICK F. BECKER ${ }^{2}$, BIMAL K. BANIK ${ }^{3}$ and Q. PING DOU ${ }^{1}$ \\ ${ }^{1}$ The Prevention Program, Barbara Ann Karmanos Cancer Institute, and Department of Pathology, \\ School of Medicine, Wayne State University, Detroit, MI; ${ }^{2}$ Department of Molecular Pathology, \\ The University of Texas M.D. Anderson Cancer Center, Houston, TX 77030; ${ }^{3}$ Department of \\ Chemistry, University of Texas-Pan American, Edinburg, TX 78541, USA
}

Received November 10, 2005; Accepted December 19, 2005

\begin{abstract}
Persistent but relatively limited research has been devoted to the use of compounds related to polycyclic aromatic hydrocarbons (PAH) as anticancer agents. In previous reports, we have described the cytotoxicity of a number of new and novel PAH against human cancer cell lines. However, the involved molecular mechanisms of inducing cell death were not elucidated. In the current study, we describe the apoptotic pathway as apparently playing a crucial role in induced cell death in human leukemia Jurkat $\mathrm{T}$ cells by several diamide and diamine PAH that contain chrysene as their core aromatic ring system. Structure-activity relationships were analyzed. Importantly, no effect was demonstrated in a normal, nontransformed line of human natural killer cells. These results provide additional evidence for the potential chemotherapeutic use of PAH.
\end{abstract}

\section{Introduction}

Persistent but relatively limited research has been focused on the use of PAH-compounds as anticancer agents. For example, Bair et al $(1,2)$ have studied a number of unique compounds of this type and have reported a close correlation between antitumor activity and the shape of their polyaromatic system. They have developed several, highly active benzylic aminopropanediols using structure-activity relationships (SAR) as the basis for synthesizing new derivatives. These compounds were believed to interact with DNA by intercalation and to

Correspondence to: Dr Q. Ping Dou, Karmanos Cancer Institute, 640.01 HWCRC, 4100 John R, Detroit, MI 48201, USA

E-mail: doup@karmanos.org

Dr Bimal K. Banik, Department of Chemistry, The University of Texas-Pan American, 1201 W University Dr, Edinburg, TX 78541, USA

E-mail: banik@panam.edu

Key words: polycyclic aromatic hydrocarbons, apoptosis, structureactivity relationships act as topoisomerase inhibitors. However, they were not able to produce a definitive correlation between the ability of these compounds to bind to DNA and the resultant cytotoxic activity $(3,4)$. Clinical studies of two of the most active of these napththalimides failed as a result of CNS toxicity. To improve the potency and the toxicity:benefit ratio, naphthalene was changed to anthracene to serve as the chromophore. While the resulting analog, azonafide, showed enhanced potency, and had many of the characteristics similar to those of other classes of DNA intercalators, it did not definitively localize in the nucleus $(5,6)$. Other differences from existing DNA intercalating agents such as mitoxantrone (7) include the failure of inhibition of topoisomerase II at equicytotoxic concentrations. Denny et al have published a number of crucial studies that raise important questions as to the exact target of a number of related compounds (8).

In the current study, we examined the apoptosis-inducing activity of several PAH that contain chrysene as the core aromatic ring system $(9,10)$. Previous examination of SAR utilizing their cytotoxicity against a number of human cancer cell lines (9-11) revealed interesting correlations of activity with modification of types and numbers of functional groups off the chrysene core. For example, while the length of the carbon chains did not confer significant differences, the presence of amine verses amide groups in these chains or modification and/or the presence of the terminal, heterocyclic rings, resulted in striking differences. However, the basis for the cytotoxicity induced by some of the highly active derivatives was not identified.

Therefore, using several of these model compounds, we have now examined the influence of SAR on the induction of the apoptotic pathway in human leukemia Jurkat $\mathrm{T}$ cells and have found it to play a crucial role. Of interest, even the most active of these compounds failed to produce any damage in normal, non-transformed natural killer cells.

\section{Materials and methods}

Reagents. Fetal bovine serum was purchased from Tissue Culture Biologicals (Tulare, CA). Mixture of penicillinstreptomycin-L-glutamine, MEM sodium pyruvate, MEM 


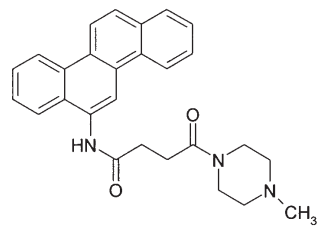

$\mathrm{Tx}-1$

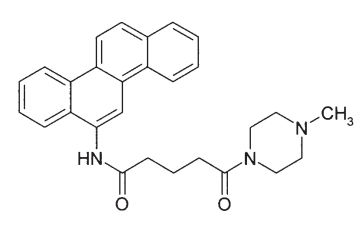

Tx-23

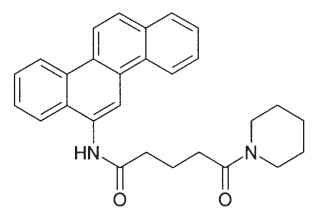

Tx-3

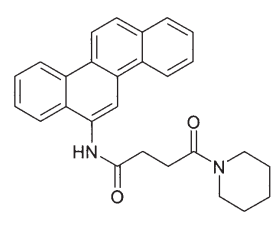

Tx-25

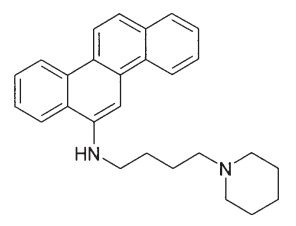

Tx-5

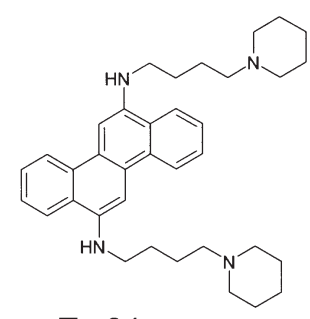

Tx-84

Figure 1. Polycyclic aromatic compounds with varying functional groups. Compounds containing a chrysene moiety with attached amide or amine chains of varying lengths and a terminal heterocyclic group with (Tx-1, Tx-23) or without (Tx-3, Tx-5, Tx-25, Tx-84) an additional amine are shown.

non-essential amino acids, and RPMI were purchased from Invitrogen (Carlsbad, CA). Dimethylsulfoxide (DMSO) and trypan blue were purchased from Sigma-Aldrich (St. Louis, MO). Fluorogenic peptide substrate Ac-DEVD-AMC (for caspase-3/-7 activities) was obtained from Calbiochem (San Diego, CA).

Synthesis of polycyclic aromatic compounds. The compounds used in this study were synthesized as described previously (9).

Cell culture, protein extraction, and Western blot assay. Human leukemic Jurkat $\mathrm{T}$ cells and non-transformed natural killer YT cells were cultured in RPMI-1640 medium, supplemented with $10 \%$ fetal bovine serum, 100 units/ml penicillin, and $100 \mu \mathrm{g} / \mathrm{ml}$ streptomycin. The YT cells were also supplemented with $1 \mathrm{mM}$ MEM sodium pyruvate and $0.1 \mathrm{mM}$ MEM non-essential amino acids solution. These cell lines were maintained at $37^{\circ} \mathrm{C}$ in a humidified incubator with an atmosphere of $5 \% \mathrm{CO}_{2}$. Monoclonal anti-mouse IgG-horseradish peroxidase was purchased from Santa Cruz Biotechnology (Santa Cruz, CA). The polyclonal antibody to poly(ADPribose) polymerase (PARP) was purchased from Biosource (Camarillo, CA). A whole-cell extract was prepared and Western blotting was performed as described previously (12).

Trypan blue assay. The trypan blue dye exclusion assay was used to ascertain cell death in Jurkat $\mathrm{T}$ cells treated with various polycyclic aromatic compounds at various time-points. Briefly, $20 \mu 1$ of cell suspension was mixed with $20 \mu 1$ of $0.4 \%$ trypan blue dye. The cell/dye mixture was loaded onto a hemocytometer. The number of cells that absorbed the dye and those that excluded the dye were counted to determine the percentage of non-viable cell number to total cell number.

Caspase-3 activity assay. To measure cell-free caspase-3 activity, whole cell extracts $(30 \mu \mathrm{g})$ from untreated or treated cells were incubated with $40 \mu \mathrm{M}$ of the fluorogenic substrate caspase-3/-7 (Ac-DEVD-AMC) for $2 \mathrm{~h}$ at $37^{\circ} \mathrm{C}$ in $100 \mu \mathrm{l}$ of assay buffer (50 mM Tris, $\mathrm{pH} 8.0$ ). Measurement of the hydrolyzed AMC groups was performed on a Wallac Victor ${ }^{3}$ Multilabel plate reader ${ }^{\mathrm{TM}}$ (Perkin-Elmer) with an excitation filter of $380 \mathrm{~nm}$ and an emission filter of $460 \mathrm{~nm}$. Changes in fluorescence were calculated and compared with vehicle control treatment and plotted with statistical analysis using Microsoft Excel ${ }^{\mathrm{TM}}$ software.

TUNEL assay. Terminal deoxynecleotydyl transferasemediated dUPT-biotin nick end-labeling (TUNEL) assay was performed using the BD PharMingen, APO-Direct ${ }^{\mathrm{TM}}$ kit (San Diego, CA). Cells were treated with varying concentrations, harvested at varying time-points, counted, and washed twice with ice-cold PBS. Briefly, approximately $2 \times 10^{6}$ cells were fixed in $1 \%$ paraformaldehyde for $15 \mathrm{~min}$ on ice, washed with PBS, and then fixed again in $70 \%$ ethanol at $-20^{\circ} \mathrm{C}$ overnight. The cells were then incubated in DNA labeling solution [containing terminal deoxynucleotidyl transferase (TdT) enzyme, fluorescein-conjugated dUTP, and reaction buffer] for $90 \mathrm{~min}$ at $37^{\circ} \mathrm{C}$. After removing the DNA labeling solution by rinsing cells with rinsing buffer, the cells were incubated with propidium iodide/RNase A solution, incubated for $30 \mathrm{~min}$ at room temperature in the dark, and then analyzed by flow cytometry within $3 \mathrm{~h}$ of staining. Fluorescence intensity was visualized and estimated for the TUNEL assay using a FACScan (Becton-Dickinson Immunocytometry, CA).

\section{Results}

Relationship of structure to cytotoxicity. The compounds utilized in this study possess a chrysene moiety as their core PAH with attached amide or amine chains of varying lengths and a terminal heterocyclic group, with or without an additional amine group (Fig. 1). Their synthesis and their cytotoxicity against a number of human tumor cell lines, using counts of surviving cell numbers, have been reported previously (9-11). In the current study, cytotoxicity against Jurkat $\mathrm{T}$ cells was first measured by trypan blue dye exclusion in both dose- and time-dependent assays. Four hours of Jurkat $\mathrm{T}$ cell exposure to a concentration of $8 \mu \mathrm{M}$ of Tx-5 resulted in approximately $45 \%$ cell death, which increased to $100 \%$ at $8 \mathrm{~h}$ (Fig. 2a). In 

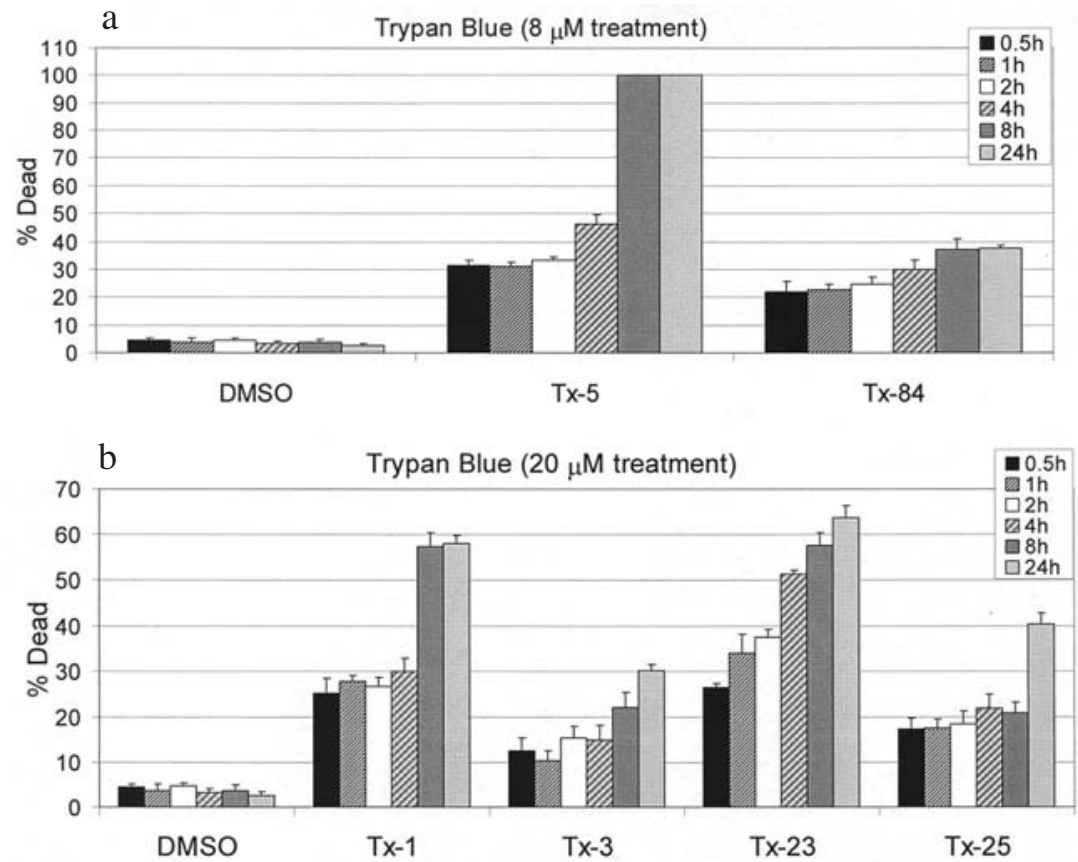

Figure 2. Structure-activity relationships via trypan blue analysis. (a) Jurkat T cells were treated with the solvent (DMSO), $8 \mu \mathrm{M}$ of Tx- 5 or Tx- 84 , for up to 24 h, followed by trypan blue incorporation assay. (b) Jurkat T cells were treated with the solvent (DMSO) or $20 \mu \mathrm{M}$ of indicated compound for up to $24 \mathrm{~h}$, followed by trypan blue incorporation assay. The data are represented as the mean number of dead cells over total cell population \pm SD and are representative of three independent experiments.
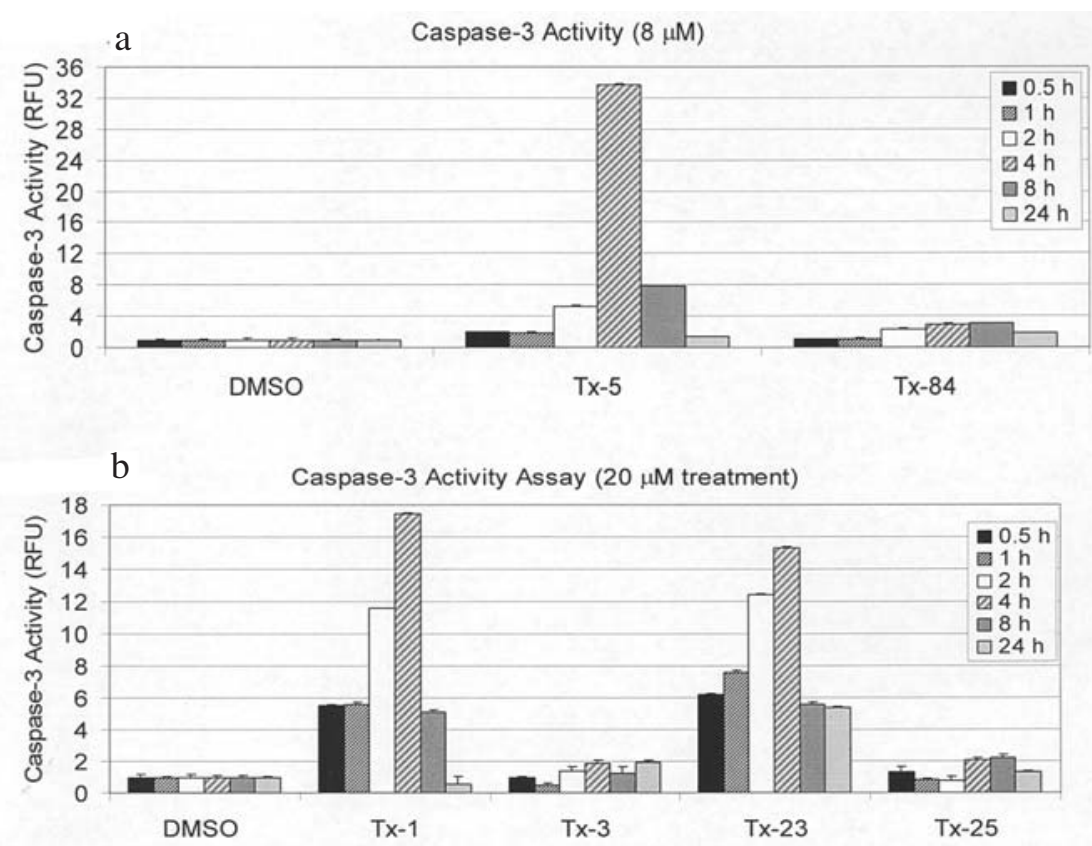

Figure 3. Tx-5 potently induces apoptosis in Jurkat T cells. Jurkat T cells were treated with the solvent (DMSO), (a) $8 \mu \mathrm{M}$ of Tx-5 or Tx-84 or (b) $20 \mu \mathrm{M}$ of Tx-1, Tx-3, Tx-23, or Tx-25 for the indicated times, followed by cell-free caspase-3 activity assay. Caspase-3 activity was determined by incubating whole cell extracts with $40 \mu \mathrm{M}$ caspase-3 substrate and measuring production of hydrolyzed 7-amido-4-methyl-coumarin (AMC) groups using a multi-label plate reader. The results are representative of 3 separate experiments.

contrast, exposure for $4 \mathrm{~h}$ to $8 \mu \mathrm{M}$ Tx-84, which possesses two identical amino chains, resulted in approximately $30 \%$ cytotoxicity, which increased by only $10 \%$ at $8 \mathrm{~h}$ with no further increase through $24 \mathrm{~h}$ (Fig. 2a).

Tx-1, Tx-3, Tx-23 and Tx-25 were tested similarly (Fig. 2b). None of these compounds produced as significant cytotoxicity as Tx-5 at $8 \mu \mathrm{M}$ and, therefore, they were tested at $20 \mu \mathrm{M}$. At this concentration, Tx-3 and Tx-25 achieved a maximum cytotoxicity of $30 \%$ and $40 \%$, respectively. Tx-1 achieved a maximum cytotoxicity of $58 \%$ at $8 \mathrm{~h}$ and $20 \mu \mathrm{M}$ while, at this concentration, Tx-23 resulted in a slightly greater cytotoxicity of approximately $63 \%$ at $24 \mathrm{~h}$.

Examination of the apoptotic pathway. To determine whether an apoptotic pathway played a role in the cytotoxicity induced in Jurkat $\mathrm{T}$ cells by these compounds, activation of caspase- 3 


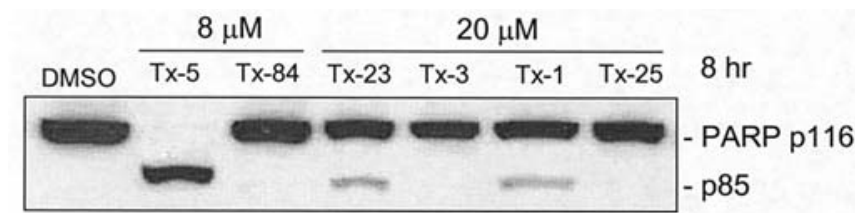

Figure 4. PARP cleavage as a result of apoptotic cell death. Jurkat T cells were treated with the solvent (DMSO), $8 \mu \mathrm{M}$ of Tx-5 or Tx-84 or $20 \mu \mathrm{M}$ of Tx-1, Tx-3, Tx-23, or Tx-25 for $8 \mathrm{~h}$. Western blot analysis was performed using specific antibodies to PARP.

was measured during exposure to the 6 compounds. When compared to solvent (DMSO) control values, exposure to Tx-5 resulted in an increase of caspase- 3 activity by $>30$-fold at $4 \mathrm{~h}$ (Fig. 3a). Exposure to Tx-84 resulted in a barely detectable increase of 3 -fold. To confirm the effect of this degree of caspase- 3 activation in Tx-5 treated cells, Western blot analysis was performed to determine the presence of cleaved PARP. Reflecting the cellular impact of this degree of caspase activation resulting from exposure to $\mathrm{Tx}-5$, a significant degree of PARP cleavage was detected in these cells (Fig. 4). In contrast, cells treated with Tx-84 demonstrated no cleavage of PARP, confirming the impression that the level of caspase increase was not significant in terms of resultant cell alteration and damage. These findings also support the impression that the caspase activity measured as a result of exposure to Tx-3 and Tx-25 of at most 2-fold, even at $20 \mu \mathrm{M}$ treatment (Fig. 3b) was not a significant contributor to cell toxicity. However, at $20 \mu \mathrm{M}, \mathrm{Tx}-1$ and $\mathrm{Tx}-23$ resulted in a maximal caspase activation of 15- and 17-fold respectively at $4 \mathrm{~h}$ and PARP cleavage was observed after $8 \mathrm{~h}$ (Fig. 4). These findings further support the possibility that the apoptotic pathway plays a role in the cytotoxicity induced by this series of compounds.

Effects on non-transformed, human natural killer cells. To determine the effect of Tx-5 on normal, non-transformed, natural killer cells, and to extend the examination of its induction of apoptosis, its effects were examined in Jurkat and YT cells using the TUNEL assay. Since B-lactams such as L-1 have been shown previously to induce apoptosis in human cancer cell lines, but not in normal cell lines (13-15), $\mathrm{L}-1$ was used as a control in this experiment. Jurkat $\mathrm{T}$ and YT cells were exposed to $8 \mu \mathrm{M}$ of Tx-5 or $10 \mu \mathrm{M} \mathrm{L}-1$ for up to $24 \mathrm{~h}$, harvested, fixed in $70 \%$ ethanol, stained (see Materials and methods) and analyzed for TUNEL positivity by flow
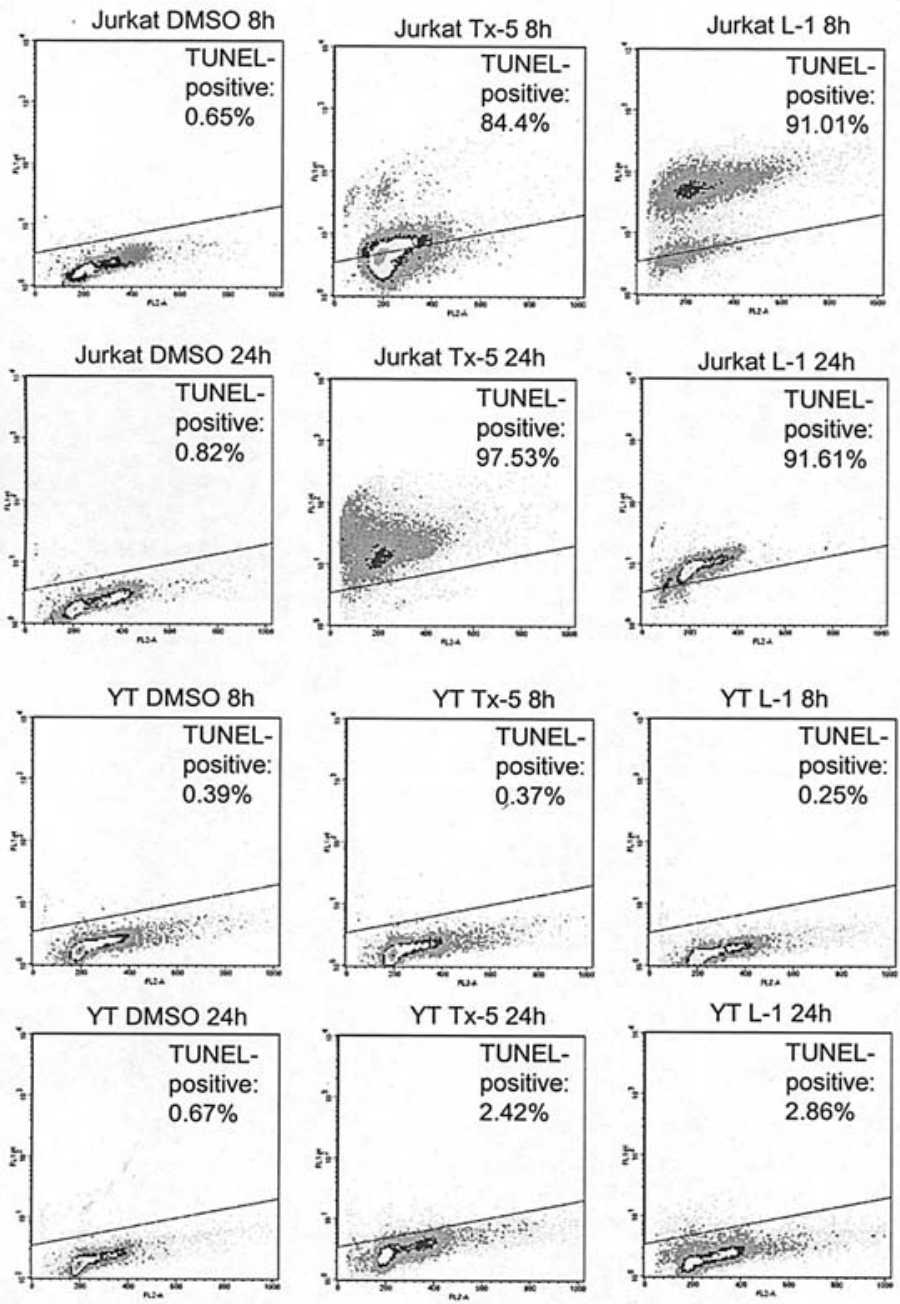

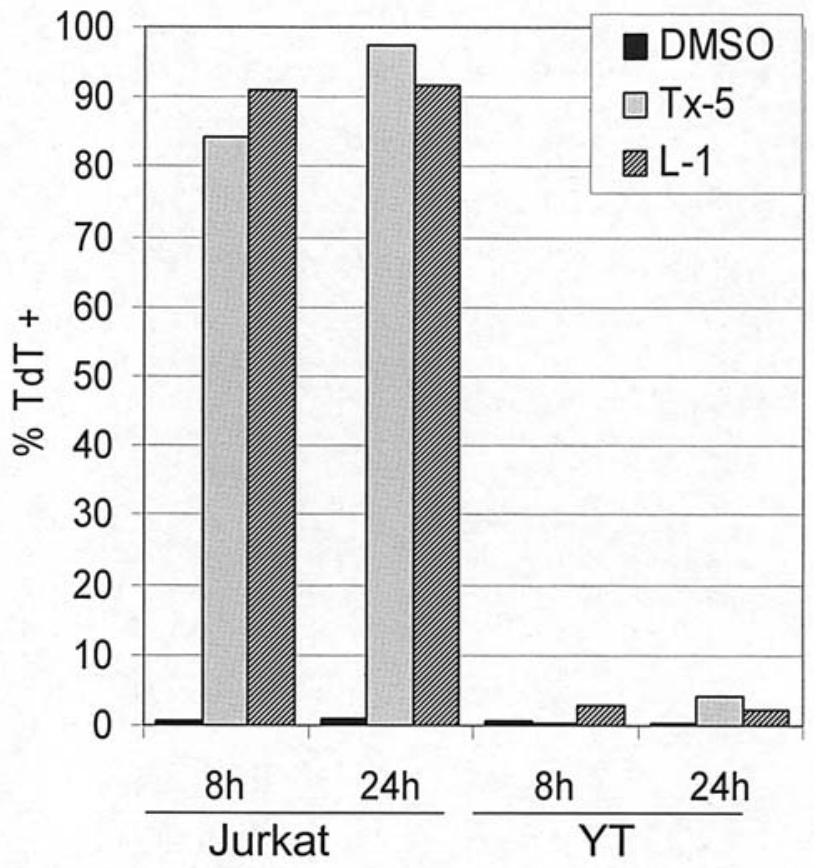

Figure 5. Tx-5 explicitly induces apoptosis in tumor cells. The TUNEL assay was performed by using an APO-Direct kit as described in Materials and methods. Jurkat T and YT cells were treated with the solvent (DMSO), $8 \mu \mathrm{M}$ Tx-5, or $10 \mu \mathrm{M}$ lactam-1 for up to $24 \mathrm{~h}$. Fluorescence intensity was estimated for the TUNEL assay using a flow cytometer. 
cytometry (Fig. 5). Jurkat cells incubated with Tx-5 were $84.4 \%$ TUNEL-positive after $8 \mathrm{~h}$ and increased to $98 \%$ after $24 \mathrm{~h}$. However, Tx-5 produced no significant difference in TUNEL positivity in YT cells when compared with control cells. L-1 produced similar results.

\section{Discussion}

The results of the study of these compounds using trypan blue dye uptake as a measure of cytotoxicity indicate a strong correlation with their chemical structure and, in general, agree with previous results that used counts of surviving cells as a measure of cell death. The most dominant determinant of cell damage was the presence of the diamine chain in Tx-5 as is especially evident when compared with the corresponding diamide derivative, Tx-25. The latter failed to induce any significant degree of caspase-3 activation and significantly lesser level of cell death, even at a 2.5-fold greater concentration. Again, as previously reported, the presence of the terminal N-methpyridinal heterocyclic ring (Tx-1 and Tx-23) was more potent than the terminal ring lacking the methyl group (Tx-3 and Tx-25). In no case did a one $\mathrm{C}$ change in chain length alter the effectiveness of the compounds.

One anomalous finding was the significantly lesser cytotoxicity of Tx-84 when compared with Tx-5, a difference that was not previously demonstrated using other human tumor lines, where Tx-84 was equally potent. We must conclude from this finding with Jurkat as the target cell, that the second diamine chain inhibits the expected cytotoxicity by an unknown mechanism. Either this results from some stereo hindrance with the reactive site within the Jukat cell, or suggests that the 12th position of the chrysene ring, which is known to be highly reactive, is required for the cytotoxicity induced by Tx-5. It is, however, further evidence of the high degree of specificity demonstrated by many anti-tumor agents.

The mechanism by which these compounds induced cytotoxicity was not previously known. The high degree of caspase- 3 activation, PARP-cleavage, and DNA damage demonstrated by the TUNEL assay as a result of exposure to Tx-5, clearly illustrate the key role played by the apoptotic pathway in the resulting cell death. In addition, the degree of caspase activation induced by $\mathrm{Tx}-1$ and $\mathrm{Tx}-23$, albeit at a higher concentration, suggests that, here too, apoptotic cell death was determinative. These results correlate perfectly with the relative percentages of cell damage as demonstrated in this and previous studies and their correlation with structureactivity.

One of the most striking findings was the absence of effect of Tx-5 against a non-transformed, natural killer cell line, YT. This further supports the probability that the effect of Tx-5 against leukemic Jurkat T cells specifically targets some aspect of tumor cell physiology, which strengthens its possible role in clinical treatment.

Finally, while there was no significantly detectable increase in caspase- 3 activation at $8 \mu \mathrm{M} \mathrm{Tx}-84$ or at $20 \mu \mathrm{M}$ Tx-3 and $\mathrm{Tx}-25$, each of these compounds induced approximately 30 $40 \%$ cell death. It should not come as a surprise that this finding suggests that alternate pathways exist for inducing cell damage, such as direct interaction with the cells' surfaces, as has been previously recognized.

\section{Acknowledgements}

The authors thank the Flow Cytometry Core at Karmanos Cancer Institute, Wayne State University, School of Medicine (Detroit, MI).

\section{References}

1. Bair KW, Andrews CW, Tuttle RL, Knick VC, Cory M and McKee DD: 2-(Arylmethyl)amino-2methyl-1,3-propanediol DNA intercalators. An examination of the effects of aromatic ring variation on antitumor activity and DNA binding. J Med Chem 34: 1983-1990, 1991.

2. Bair KW, Tuttle R, Knick VC, Cory M and McKee DD: (1Pyrenylmethyl)amino alcohols, a new class of antitumor DNA intercalators. Discovery and initial amine side chain structureactivity studies. J Med Chem 33: 2385-2393, 1990.

3. Malviya VK, Liu PY, Alberts DS, Surwit EA, Craig JB and Hanningan EV: Evaluation of amonafide in cervical cancer phase II. Am J Clin Oncol 15: 41-44, 1992.

4. Rosell R, Carles J, Abad A, Ribelles N, Barnadas A, Benavides A and Martin M: Phase I study of mitonafide in $120 \mathrm{~h}$ continuous infusion in non-small cell lung cancer. Invest New Drugs 10: 171-175, 1992.

5. Sami SM, Dorr RT, Alberts DS and Remers WA: 2-Substituted 1,2-dihydro-3H-dibenz[de,h]isoquinoline-1,3-diones. A new class of anti-tumor agent. J Med Chem 19: 765-770, 1993.

6. Sami SM, Dorr RT, Solyion AM, Alberts DS and Remers WA: Amino-substituted 2-[2/-(dimethylamino)ethyl]-1,2-dihydro3H-dibenz[de,h]isoquinoline-1,3-diones. Synthesis, anti-tumor activity and quantitative structure-activity relationship. J Med Chem 38: 983-993, 1995.

7. Fukushima T, Kawai Y, Nakayama T, Yamaguchi T, Yoshida A, Urasaki Y, Imamura S, Kamiya K, Tsutani H, Ueda T and Nakamura T: Superior cytotoxic potency of mitoxantrone in interaction with DNA: comparison with that of daunorubicin. Oncol Res 8: 95-100, 1996.

8. Denny WA, Rewcastle GW and Baguley BC: Potential antitumor agents. 59. Structure-activity relationships for 2-phenylbenzimidazole-4-carboxamides, a new class of 'minimal' DNAintercalating agents which may not act via topoisomerase II. J Med Chem 33: 814-819, 1990.

9. Banik BK and Becker FF: Polycyclic aromatic compounds as anticancer agents: structure-activity relationships of chrysene and pyrene derivatives. Bioorg Med Chem 9: 593-605, 2001.

10. Becker FF and Banik BK: Polycyclic aromatic compounds as anticancer agents: synthesis and biological evaluation of some chrysene derivatives. Bioorg Med Chem Lett 8: 2877-2880 1998.

11. Banik BK and Becker FF: Synthesis, electrophilic substitution and structure-activity relationship studies of polycyclic aromatic compounds for the development of anticancer agents. Curr Med Chem 8: 1513-1533, 2001.

12. An B and Dou QP: Cleavage of retinoblastoma protein during apoptosis: an interleukin 1 beta-converting enzyme-like protease as candidate. Cancer Res 56: 438-442, 1996.

13. Smith DM, Kazi A, Smith L, Long TE, Heldreth B, Turos E and Dou QP: A novel beta-lactam antibiotic activates tumor cell apoptotic program by inducing DNA damage. Mol Pharmacol 61: 1348-1358, 2002.

14. Kazi A, Hill R, Long TE, Kuhn DJ, Turos E and Dou QP: Novel $\mathrm{N}$-thiolated beta-lactam antibiotics selectively induce apoptosis in human tumor and transformed, but not normal or non-transformed, cells. Biochem Pharmacol 67: 365-374, 2004.

15. Kuhn DJ, Wang Y, Minic V, Coates C, Reddy GS, Daniel KG, Shim JY, Chen D, Landis-Piwowar KR, Miller FR, Turos E and Dou QP: Structure-activity relationships of N-methylthiolated beta-lactam antibiotics with $\mathrm{C} 3$ substitutions and their selective induction of apoptosis in human cancer cells. Front Biosci 10: 1189-1190, 2005 . 